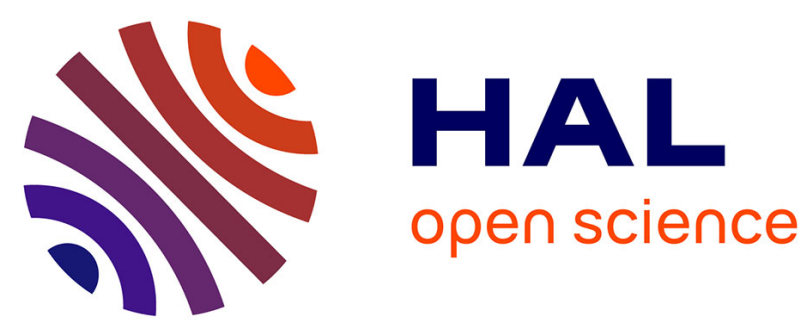

\title{
Whole genome sequences to assess the link between antibiotic and metal resistance in three coastal marine bacteria isolated from the mummichog gastrointestinal tract
}

\author{
Nicole A Lloyd, Sylvie Nazaret, Tamar Barkay
}

\section{To cite this version:}

Nicole A Lloyd, Sylvie Nazaret, Tamar Barkay. Whole genome sequences to assess the link between antibiotic and metal resistance in three coastal marine bacteria isolated from the mummichog gastrointestinal tract. Marine Pollution Bulletin, 2018, 135, pp.514-520. 10.1016/j.marpolbul.2018.07.051 . hal-02335487

\section{HAL Id: hal-02335487 \\ https://hal.science/hal-02335487}

Submitted on 29 Oct 2019

HAL is a multi-disciplinary open access archive for the deposit and dissemination of scientific research documents, whether they are published or not. The documents may come from teaching and research institutions in France or abroad, or from public or private research centers.
L'archive ouverte pluridisciplinaire HAL, est destinée au dépôt et à la diffusion de documents scientifiques de niveau recherche, publiés ou non, émanant des établissements d'enseignement et de recherche français ou étrangers, des laboratoires publics ou privés. 


\title{
Whole genome sequences to assess the link between antibiotic and metal resistance in three coastal marine bacteria isolated from the mummichog gastrointestinal tract
}

\author{
Nicole A. Lloyd ${ }^{\mathrm{a}, *}$, Sylvie Nazaret ${ }^{\mathrm{b}}$, Tamar Barkay ${ }^{\mathrm{a}}$ \\ a Department of Biochemistry and Microbiology, Rutgers University, 76 Lipman Drive, New Brunswick, NJ 08901, USA \\ ${ }^{\text {b UMR }} 5557$ Ecologie Microbienne, CNRS, INRA, VetagroSup, UCBL, Université de Lyon, 43 Boulevard du 11 Novembre, F-69622 Villeurbanne, France
}

\begin{abstract}
A B S T R A C T
Antibiotic resistance is a global public health issue and metal exposure can co-select for antibiotic resistance. We examined genome sequences of three multi-drug and metal resistant bacteria: one Shewanella sp., and two Vibrio spp., isolated from the gut of the mummichog fish (Fundulus heteroclitus). Our primary goal was to understand the mechanisms of co-selection. Phenotypically, the strains showed elevated resistance to arsenate, mercury, and various types of $\beta$-lactams. The genomes contained genes of public health concern including one carbapenemase ( $\left.b l a_{\mathrm{OXA}-48}\right)$. Our analyses indicate that the co-selection phenotype is mediated by chromosomal resistance genes and cross-resistance. No evidence of co-resistance was found; most resistance genes were chromosomally located. Moreover, the identification of many efflux pump gene homologs indicates that cross-resistance and/or co-regulation may further contribute to resistance. We suggest that the mummichog gut microbiota may be a source of clinically relevant antibiotic resistance genes.
\end{abstract}

\section{Introduction}

Antimicrobial resistance is a pressing public health concern that threatens the usage of effective antibiotic therapies and the global healthcare system. Multi-drug resistance (MDR) in Gram-negative bacteria is currently increasing at an alarming rate (Ventola, 2015). Antibiotic resistance genes (ARGs) are found in many environments (Pal et al., 2016) including ancient (30,000 year-old) permafrost sediments (D'Costa et al., 2006). Environmental reservoirs of resistance genes remain poorly understood (Allen et al., 2010). In order to combat the growing threat of MDR, it is important to understand the processes and pathways by which MDR is created and spread in the environment.

The aquatic environment is increasingly being recognized as an important reservoir for ARGs (Kang et al., 2016). Exposure to a plethora of persistent contaminants, including metals, promotes the selection of resistant indigenous microbiota. Coastal marine environments, at the boundary between terrestrial, freshwater, and marine environments, are of particular importance in this paradigm as they are locations with large and rapidly growing population centers (Culliton, 1998). The release of contaminants to productive coastal ecosystems where ARGs may spread and be selected for, may lead to the exposure of large human population centers to antibiotic-resistant bacterial pathogens (Zhu et al., 2017). For this reason, estuaries, typical ecosystems at the land-sea boundary, have been a focus of much research on the effect of environmental contamination on the spread of antibiotic resistant bacteria and ARGs for quite some time (Lu et al., 2015).

Exposure to contaminants, especially metals, may promote the spread of antibiotic resistance in the environment through a process known as co-selection (Baker-Austin et al., 2006). Co-selection is mediated through several mechanisms including co-resistance, crossresistance, and co-regulation. Co-resistance occurs when genes encoding for antibiotic and metal resistances are located proximally to each other in a genome, particularly on mobile genetic elements. Horizontal gene transfer of ARGs has been widely studied, and conjugation is generally considered the most common mechanism (Pal et al., 2017). Generally, co-resistance plasmids are commonly found in bacteria isolated from humans or domestic animals (Pal et al., 2015). Another mechanism by which co-selection occurs is via cross-resistance, when the same system (e.g. efflux pumps) confers resistance to both antibiotics and metals (Baker-Austin et al., 2006). Multidrug efflux pumps are wide-spread and well-conserved elements thought to have evolved for life in enteric environments (Blanco et al., 2016). They are known to extrude a wide range of substrates from the cell, not only antibiotics and metals, but also plant-produced compounds, quorum sensing signals, and bacterial metabolites (Blanco et al., 2016). While there is still a lack of knowledge on some of the specificities of these pumps, particularly about how they are regulated, efflux systems have been identified as contributing to MDR in Enterobacteriaceae (Webber et al., 2003). The third way by which co-selection occurs is through the transcriptional co-regulation of resistance genes. For example, heavy

\footnotetext{
* Corresponding author at: 76 Lipman Drive, New Brunswick, NJ 08901, USA.

E-mail address: nicole.lloyd@rutgers.edu (N.A. Lloyd).
} 
metal ions can increase regulation of efflux systems (e.g. the AcrAB efflux pump in E. coli), which results in increased resistance towards antibiotics (Seiler et al., 2012). While numerous studies have documented the occurrence of MDR among environmental microbes (e.g., (Kang et al., 2016; Lima-Bittencourt et al., 2007) and reviewed in: (Wright et al., 2006)), few have examined the molecular mechanisms responsible for this phenomenon.

We previously reported on the isolation of multi-drug and mercury resistant bacteria from the mummichog (Fundulus heteroclitus) gastrointestinal tract and showed that mercury resistant strains were more likely than sensitive strains to be resistant to multiple antibiotics (Lloyd et al., 2016). These results led us to consider the mechanisms that facilitate co-selection of metal and antibiotic resistances in our isolates. Here we used the power of whole genome sequencing to identify antibiotic resistance genes and their association with metal resistance genes in two Vibrio spp. and one Shewanella sp., which are known to make up a large portion of the wild mummichog gut intestinal microbial community (Givens et al., 2015). These strains belong to genera that include opportunistic pathogens and are considered vehicles of MDR (Janda, 2014; Yousfi et al., 2017a). Shewanella spp., primarily, $S$. algae and $S$. putrefraciens, have been implicated in human infections (Cimmino et al., 2016) and are known to harbor ARGs of public concern (Yousfi et al., 2017b). Vibrio are abundant in coastal waters, and their ability to develop and acquire ARGs in response to selective pressure and to further spread ARGs by horizontal gene transfer has been documented (Dang et al., 2009). Vibrio parahaemolyticus is a causative agent of food poisoning. $V$. antiquarius is a recently discovered species of Vibrio and it has not been shown to be pathogenic to humans, however, its genome does contain genes involved in pathogenicity.

Our results indicate that while the aquatic bacteria studied did indeed harbor many ARGs of clinical importance, evidence for co-resistance in the genomes was unfounded. Rather, we found evidence to support chromosomally-encoded resistance genes as well as potentially cross-resistance and/or co-regulation as mechanisms of co-selection of MDR and metal resistance.

\section{Methods}

\subsection{Isolation}

Strains were isolated from mummichog (Fundulus heteroclitus) gut ingesta collected from Berry's Creek in Bergen County, New Jersey, and Great Bay, part of Rutgers University Marine Field Station in Tuckerton, New Jersey during the summer of 2014. For details on isolation methods, refer to Lloyd et al. (2016). To taxonomically identify the strains at the genus level, colony PCR of the partial 16S rRNA gene was performed using the 27F/519R universal primers (Lane, 1991) and the sequences were compared to NCBI (Madden, 2002).

\subsection{Antibiotic susceptibility testing}

Antibiotic susceptibility to the following 14 compounds $(0.125-64 \mu \mathrm{g} / \mathrm{mL})$ was carried out by the broth microdilution method according to the guidelines of the Clinical Laboratory Standards Institute (CLSI) using microtiter plates: cefazolin, cefoperazone, cefradine, ceftazidime, kanamycin, meropenem, nalidixic acid, penicillin, sulfamethoxazole, streptomycin, tetracycline, ticarcillin, ticarcillinclavulanic acid, and vancomycin. Additionally, all strains were tested by the disk diffusion method for their susceptibility to amikacin $(30 \mu \mathrm{g})$, aztreonam $(30 \mu \mathrm{g})$, cefepime $(30 \mu \mathrm{g})$, cefoxitin $(30 \mu \mathrm{g})$, cefpirome $(30 \mu \mathrm{g})$, ceftazidime $(30 \mu \mathrm{g})$, chloramphenicol $(30 \mu \mathrm{g})$, ciprofloxacin $(5 \mu \mathrm{g})$, doripenem $(10 \mu \mathrm{g})$, gentamicin $(15 \mu \mathrm{g})$, imipenem $(10 \mu \mathrm{g})$, levofloxacin $(5 \mu \mathrm{g})$, meropenem $(10 \mu \mathrm{g})$, minocycline $(30 \mu \mathrm{g})$, netilmicin $(30 \mu \mathrm{g})$, ofloxacin $(5 \mu \mathrm{g})$, pefloxacin $(5 \mu \mathrm{g})$, piperacillin $(75 \mu \mathrm{g})$, piperacillin-tazobactam $(75 / 10 \mu \mathrm{g})$, rifampicin $(30 \mu \mathrm{g})$, tetracycline $(30 \mu \mathrm{g})$, ticarcillin $(75 \mu \mathrm{g})$, ticarcillin-clavulanic acid $(75 / 10 \mu \mathrm{g})$, tobramycin
$(10 \mu \mathrm{g})$, trimethoprim-sulfamethoxazole $(1.25 / 23.75 \mu \mathrm{g})$. Testing was performed according to the guidelines of the CLSI using commercially available disks (Bio-Rad, Marne-la-Coquette, France). Since resistance profiles are not well established for environmental bacteria, prior reports including the Enterobacteriaceae table (Soussy et al., 2013), clinical break points (Clincal Laboratory Standards Institute, 2012), and Vibrio breakpoints (Bier et al., 2015) were used in combination to determine resistance.

\subsection{Metal susceptibility testing}

Metal resistance testing was carried out using the Bioscreen C (Oy Growth Labs Ab Ltd), an automated microbiology growth curve analysis system. Pre-cultures were grown on solid tryptic soy agar media overnight at $28{ }^{\circ} \mathrm{C}$. Colonies were suspended in tryptic soy broth liquid media to a McFarland standard of $\sim 1.5$ measured using the Densicheck system (bioMérieux, Craponne, France). Approximately $4.5 \times 10^{6} \mathrm{CFU} /$ $\mathrm{mL}$ were inoculated into Bioscreen $\mathrm{C}$ honeycomb plates containing various concentrations of the following (freshly prepared) metals: nickel chloride hexahydrate (1-16 mM), cadmium chloride hemi(pentahydrate) $(0.31-10 \mathrm{mM})$, mercury (II) chloride $(12.5-200 \mu \mathrm{M})$, potassium arsenate $(3.12-200 \mathrm{mM})$, and sodium arsenite $(3.12-50 \mathrm{mM})$, with uninoculated media as a negative control, and cultures grown in the absence of metals as a positive control. Assays were run in triplicate wells. Bioscreen plates were incubated at $28^{\circ} \mathrm{C}$, with agitation, and OD at $600 \mathrm{~nm}$ measurements were taken every $20 \mathrm{~min}$.

\subsection{Growth rate calculations}

Growth rates $(\mu)$ of the triplicate wells from the Bioscreen C assays were determined using the grofit package for $\mathrm{R}$ (Kahm et al., 2010). Briefly, media blanks were subtracted from absorbance readings from raw Bioscreen data. These corrected values were analyzed in grofit. The averages and standard deviations of the growth rates were visualized in Microsoft Excel.

\subsection{DNA extraction}

Strains were grown overnight in LB liquid media amended with $100 \mu \mathrm{g} / \mathrm{mL}$ ampicillin. Genomic DNA was extracted using the QIAamp DNA Mini Kit (Qiagen). Plasmid DNA was extracted using the Macherey-Nagel Plasmid DNA purification kit (Macherey-Nagel, Hoerdt, France). Genomic and plasmid DNA samples were combined and sent to Molecular Research DNA Labs in Shallowater, TX, USA, for sequencing according to company protocols.

\subsection{Annotation and analysis}

Reads were assembled into contigs using SPAdes Genome Assembler (Bankevich et al., 2012). Genomes were annotated using the NCBI Prokaryotic Pipeline (Tatusova et al., 2016) and genome sequences are available under the assembly numbers reported in Table 1 . Average Nucleotide Identity (ANI) (Yoon et al., 2017) was calculated using the whole genome sequences. Genomes were examined using Geneious version 10 (www.geneious.com; (Kearse et al., 2012)). Potential plasmids were identified as contigs with high copy numbers (since they were extracted separately) in sequencing data. We then searched for plasmid maintenance gene homologs and as well as comparison to known plasmids. Genomic Islands were identified using IslandViewer 4 (Bertelli et al., 2017). Putative AMR genes were detected by a blast (Madden, 2002) search using ARG-ANNOT V3 March 2017, accessed November 2017 (Gupta et al., 2013). Putative metal resistance genes were detected by a blast search using the experimentally-confirmed BacMet metal resistance genes database version 1.1 (Pal et al., 2013) accessed December 2017. Gene homologs from both databases with E values $<10 \mathrm{e}^{-20}$ are reported. Efflux pump genes were identified using 
Table 1

Genome features of the three strains sequenced in this study.

\begin{tabular}{|c|c|c|c|}
\hline & \multicolumn{3}{|l|}{ Strains } \\
\hline & Vibrio sp. T9 & Vibrio sp. T21 & Shewanella sp. BC20 \\
\hline Isolated from & Great Bay & Great Bay & Berry's Creek \\
\hline $\begin{array}{l}\text { NCBI assembly } \\
\text { ID }\end{array}$ & GCF_003123985.1 & GCF_003123995.1 & GCF_003129585.1 \\
\hline $\begin{array}{l}\text { Genome } \\
\text { coverage }\end{array}$ & $41 \times$ & $49 \times$ & $59 \times$ \\
\hline $\begin{array}{l}\text { Closest } \\
\qquad \begin{array}{l}\text { available } \\
\text { genome } \\
\text { and ANI } \\
\text { score }(\%)\end{array}\end{array}$ & $\begin{array}{l}\text { Vibrio antiquarius } \\
\text { EX25 }(98.30 \%)\end{array}$ & $\begin{array}{l}\text { Vibrio } \\
\text { parahaemolyticus } \\
\text { FORC } 018 \\
(98.19 \%)\end{array}$ & $\begin{array}{l}\text { Shewanella sp. MR-4 } \\
(95.14 \%)\end{array}$ \\
\hline $\begin{array}{l}\text { Chromosome } \\
\text { size } \\
\text { (megabase } \\
\text { pairs) }\end{array}$ & 5.2 & 4.9 & 4.7 \\
\hline Chromosomes & 2 & 2 & 1 \\
\hline Plasmids & 1 & none & none \\
\hline $\begin{array}{l}\text { Plasmid size } \\
\text { and GC\% }\end{array}$ & $\begin{array}{l}120 \mathrm{~kb} \\
44.7\end{array}$ & & \\
\hline Protein-CDSs & 4891 & 4525 & 4099 \\
\hline GC (\%) & 45.0 & 45.4 & 48.0 \\
\hline \# contigs & 70 & 77 & 54 \\
\hline
\end{tabular}

the BacMet database as well as manual scanning of the genome annotations. Metal resistance and antibiotic resistance genes were referenced with results of IslandViewer 4, to visualize if any resistance gene determinants were also on putative genomic islands. To determine the sub-groups of the p-type ATPase proteins, 80 representative p-type ATPases (Smith et al., 2014) were downloaded from UniProtKB (Bairoch et al., 2007), and a phylogenetic tree (not shown) was built from the alignment of the proteins.

\section{Results}

\subsection{Taxonomic identification and genomic properties}

Among the 52 bacteria we isolated from the mummichog gut microbiome, the two most dominant taxa were Vibrio (62\%) and Shewanella (21\%) (Fig. S1). Shewanella sp. BC20 was isolated from the gut ingesta of fish collected from Berry's Creek, an EPA superfund site contaminated with mercury and arsenic, located in New Jersey, USA (Wright et al., 2010). Vibrio spp. T9 and T21 were isolated from the gut ingesta of mummichog fish collected from Great Bay, New Jersey, USA, a relatively uncontaminated site (Lloyd et al., 2016). The average nucleotide identities (ANI) with scores above $95 \%$ were used to identify the available genome to which our strains were most closely related. Of those available in NCBI as of May 2016, Shewanella BC20 was most closely related to Shewanella sp. MR-4, a strain isolated from the water

Table 2

Antibiotic MICs/measures of zone of inhibition profiles and resistance interpretation of the three strains in this study.

\begin{tabular}{|c|c|c|c|c|c|c|}
\hline \multirow[b]{2}{*}{ Drug } & \multicolumn{2}{|c|}{ Vibrio sp. T9 } & \multicolumn{2}{|c|}{ Vibrio sp. T21 } & \multicolumn{2}{|c|}{ Shewanella sp. BC20 } \\
\hline & $\begin{array}{c}\text { Zone of } \\
\text { Inhibition } \\
(\mathrm{mm})^{*}\end{array}$ & Interpretation & $\begin{array}{c}\text { Zone of } \\
\text { Inhibition } \\
(\mathrm{mm})\end{array}$ & Interpretation & $\begin{array}{c}\text { Zone of } \\
\text { Inhibition } \\
(\mathrm{mm})\end{array}$ & Interpretation \\
\hline Doripenem & $\geq 24$ & $\mathrm{~S} * *$ & $\geq 24$ & $\mathrm{~S}$ & $\leq 21$ & $\mathrm{R}$ \\
\hline Imipenem & $\geq 22$ & $\mathrm{~S}$ & $\geq 22$ & $\mathrm{~S}$ & $\leq 16$ & $\mathrm{R}$ \\
\hline Meropenem & $\geq 22$ & $\mathrm{~S}$ & $\geq 22$ & $\mathrm{~S}$ & $\leq 16$ & $\mathrm{R}$ \\
\hline Piperacillin & $\leq 17$ & $\mathrm{R}^{* * *}$ & $\leq 17$ & $\mathrm{R}$ & $\leq 17$ & $\mathrm{R}$ \\
\hline $\begin{array}{l}\text { Piperacillin - } \\
\text { Tazobactam }\end{array}$ & $\geq 20$ & $\mathrm{~S}$ & $\geq 20$ & $\mathrm{~S}$ & $\leq 17$ & $\mathrm{R}$ \\
\hline Ticarcillin & $\leq 23$ & $\mathrm{R}$ & $\leq 23$ & $\mathrm{R}$ & $\leq 23$ & $\mathrm{R}$ \\
\hline $\begin{array}{c}\text { Ticarcillin - } \\
\text { Clavulanic Acid }\end{array}$ & $\leq 23$ & $\mathrm{R}$ & $\leq 23$ & $\mathrm{R}$ & $\leq 23$ & $\mathrm{R}$ \\
\hline Ofloxacin & $\geq 22$ & $\mathrm{~S}$ & $\leq 22$ & I & $\geq 22$ & $\mathrm{~S}$ \\
\hline Amikacin & $\geq 17$ & $\mathrm{~S}$ & $\leq 17$ & $\mathrm{I}$ & $\geq 17$ & $\mathrm{~S}$ \\
\hline Tobramicin & $\leq 17$ & $\mathrm{I}$ & $\leq 17$ & $\mathrm{I}$ & $\geq 17$ & $\mathrm{~S}$ \\
\hline Chloramphenicol & $\geq 17$ & $\mathrm{~S}$ & $\geq 17$ & $\mathrm{~S}$ & $\geq 17$ & $\mathrm{~S}$ \\
\hline Drug & MIC* & Interpretation & MIC* & Interpretation & MIC* & Interpretation \\
\hline Meropenem & 0 & $\mathrm{~S}$ & 0 & $\mathrm{~S}$ & 16 & $\mathrm{R}$ \\
\hline Cefoperazone & 64 & $\mathrm{R}$ & 64 & $\mathrm{R}$ & 32 & $\mathrm{R}$ \\
\hline Ceftazidime & 64 & $\mathrm{R}$ & 64 & $\mathrm{R}$ & 64 & $\mathrm{R}$ \\
\hline Cefazolin & 0.5 & $\mathrm{~S}$ & 4 & $\mathrm{~S}$ & 64 & $\mathrm{R}$ \\
\hline Cefradine & 8 & $\mathrm{~S}$ & 64 & $\mathrm{R}$ & 2 & $\mathrm{~S}$ \\
\hline Ticarcillin & 64 & $\mathrm{R}$ & 64 & $\mathrm{R}$ & 64 & $\mathrm{R}$ \\
\hline Penicillin & 64 & $\mathrm{R}$ & 64 & $\mathrm{R}$ & 64 & $\mathrm{R}$ \\
\hline $\begin{array}{c}\text { Ticarcillin - } \\
\text { Clavulanic Acid }\end{array}$ & 16 & $\mathrm{R}$ & 32 & $\mathrm{R}$ & 64 & $\mathrm{R}$ \\
\hline Vancomycin & 2 & $\mathrm{~S}$ & 8 & $\mathrm{~S}$ & 32 & $\mathrm{R}$ \\
\hline Nalidixic Acid & 0.5 & $\mathrm{~S}$ & 1 & $\mathrm{~S}$ & 2 & $\mathrm{~S}$ \\
\hline $\begin{array}{c}\text { Sulfamethoxazol } \\
\text { e }\end{array}$ & 2 & $\mathrm{~S}$ & 8 & $\mathrm{~S}$ & 64 & $* * * *$ \\
\hline Tetracycline & 0 & $\mathrm{~S}$ & 0.125 & $\mathrm{~S}$ & 1 & $\mathrm{~S}$ \\
\hline
\end{tabular}

*Levels of resistance are reported in MIC $\mu \mathrm{g} / \mathrm{mL}$ (for those tested with the microdilution method) or zone of inhibition in mm (for those tested with the disk method).

**Organisms are reported as S (sensitive), I (intermediate), or R (resistant) as established by common standards. For a complete list of all antibiotics tested, and sources for common standards used in determining break points, see Table S1.

$* * *$ Shading indicates that a resistance gene homolog potentially conferring resistance to that antibiotic was found in the genome regardless if the strain was phenotypically resistant or sensitive to that drug. $* * * *$ Comparable resistance breakpoints for this drug could not be found. 
Table 3

Antibiotic resistance gene homologs with clinical relevance and their respective locus tags in the three genomes.

\begin{tabular}{|c|c|c|c|c|c|}
\hline & & & Vibrio sp. T9 & Vibrio sp. T21 & Shewanella sp. BC20 \\
\hline Antibiotic class & Putative gene & Substrates/function & Locus & Locus & Locus \\
\hline \multirow[t]{4}{*}{$\beta$-lactams } & Class A $\beta$-lactamase (CARB) & Penicillins, cephalosporins, carbenicillin (Chiou et al., 2015) & CBX98_10150 & CCD93_08640 & \\
\hline & Class B metallo $\beta$-lactamase & Broad spectrum, including carbapenems, (Palzkill, 2013) & CBX98_12520 & CCD93_19270 & CBX96_13965 \\
\hline & Class C $\beta$-lactamase & Cephalosporins (Bush et al., 2010) & CBX98_08735 & & CBX96_05400 \\
\hline & Class D $\beta$-lactamase (bla $\left.a_{\text {OXA } 48}\right)$ & Penicillins and carbapenems (Bush et al., 2010) & & & СВX96_07750 \\
\hline \multirow[t]{2}{*}{ Tetracyclines } & tet34 & Oxytetracycline mechanisms (Nonaka et al., 2002) & CBX98_18940 & CCD93_18545 & \\
\hline & tet35 & Efflux of tetracycline (Teo et al., 2002) & CBX98_02340 & CCD93_18785 & \\
\hline Fluoroquinolones & $q n r S$ & Quinolones (Hooper et al., 2015) & CBX98_12495 & CCD93_19295 & \\
\hline
\end{tabular}

* The table shows select antibiotic resistance gene homologs located in the genome.

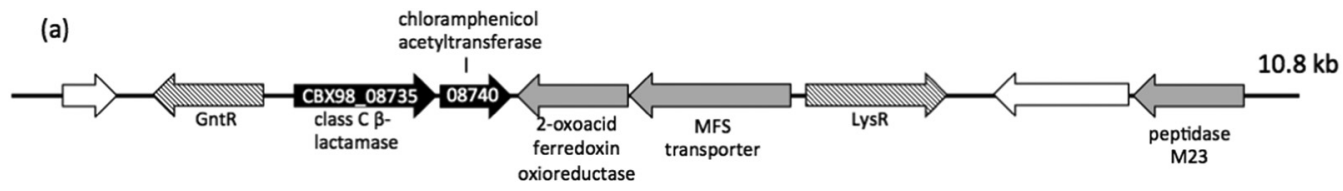

(b)

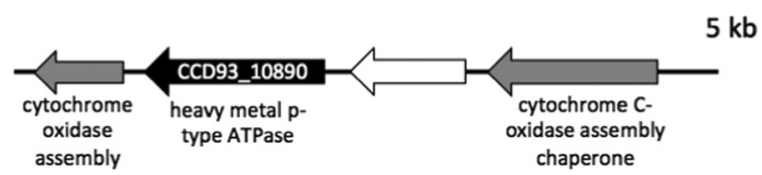

column of the Black Sea at a depth of $5 \mathrm{~m}$ (Nealson et al., 1991). Vibrio sp. T9 was most closely related to Vibrio antiquarius EX25, a Vibrio isolated from hydrothermal vents (Hasan et al., 2015), and Vibrio sp. T21 was most closely related to Vibrio parahaemolyticus FORC 018, a strain isolated from sea bass in South Korea (Table 1). Shewanella sp. BC20 had an average G + C\% of $48.0 \%$, which is identical to that reported for Shewanella sp. MR-4. (GenBank Accession CP000446.1). The genome of Shewanella sp. BC20 contained no plasmids (Table 1). The average $\mathrm{G}+\mathrm{C} \%$ of the two Vibrio strains, Vibrio spp. T9 and T21, were 45.0 and $45.4 \%$, respectively, which is within the normal range for Vibrio species (Hasan et al., 2015). Strain Vibrio sp. T9 contained one $120 \mathrm{~kb}$ plasmid, with a $\mathrm{G}+\mathrm{C} \%$ of $44.7 \%$, close to that of the chromosome. The plasmid showed $94 \%$ nucleotide identity (with $65 \%$ query cover) to $V$. alginolyticus ATCC 33787 plasmid pMBL128 (Accession number CP013486.1).

\subsection{Antibiotic susceptibility profiles}

Resistance to 33 antibiotics was tested using established procedures, a combination of the disk method and the microdilution method (Tables 2, S1). Of those drugs tested with both the disk method and the microdilution method, we obtained consistent results among carbapenems, penicillins, tetracyclines, and most cephalosporins. All three strains showed broad resistance to $\beta$-lactams, primarily cephalosporins and penicillins. The two Vibrio strains were intermediately resistant to aminoglycosides. The resistance profile of Shewanella sp. BC20 was varied, including resistance to carbapenems as well as to vancomycin. All strains were sensitive to tetracycline and chloramphenicol.

\subsection{Antibiotic resistance genes}

Overall, our analysis identified 70 potential ARG homologs in Shewanella sp. BC20, 78 were identified in Vibrio sp. T21, and 89 in Vibrio sp. T9 (Tables S2, S3, S4). ARG homologs of clinical relevance are reported (Table 3). All four Ambler classes of $\beta$-lactamases were identified among the three strains. All three harbored class B metallo- $\beta$ lactamases. Vibrio sp. T9 contained a class $C \beta$-lactamase located on a
Fig. 1. Genomic Islands containing genes of interest located in Vibrio sp. T9 (A) and Vibrio sp. T21 (B). The genomic island in (A) contains two antibiotic resistance genes and the island in (B) contains one metal resistance gene (colored black). Hypothetical proteins are colored white, genes involved in transcriptional regulation are shaded with diagonal lines, and all other genes are in grey. Arrows indicate direction of transcription.

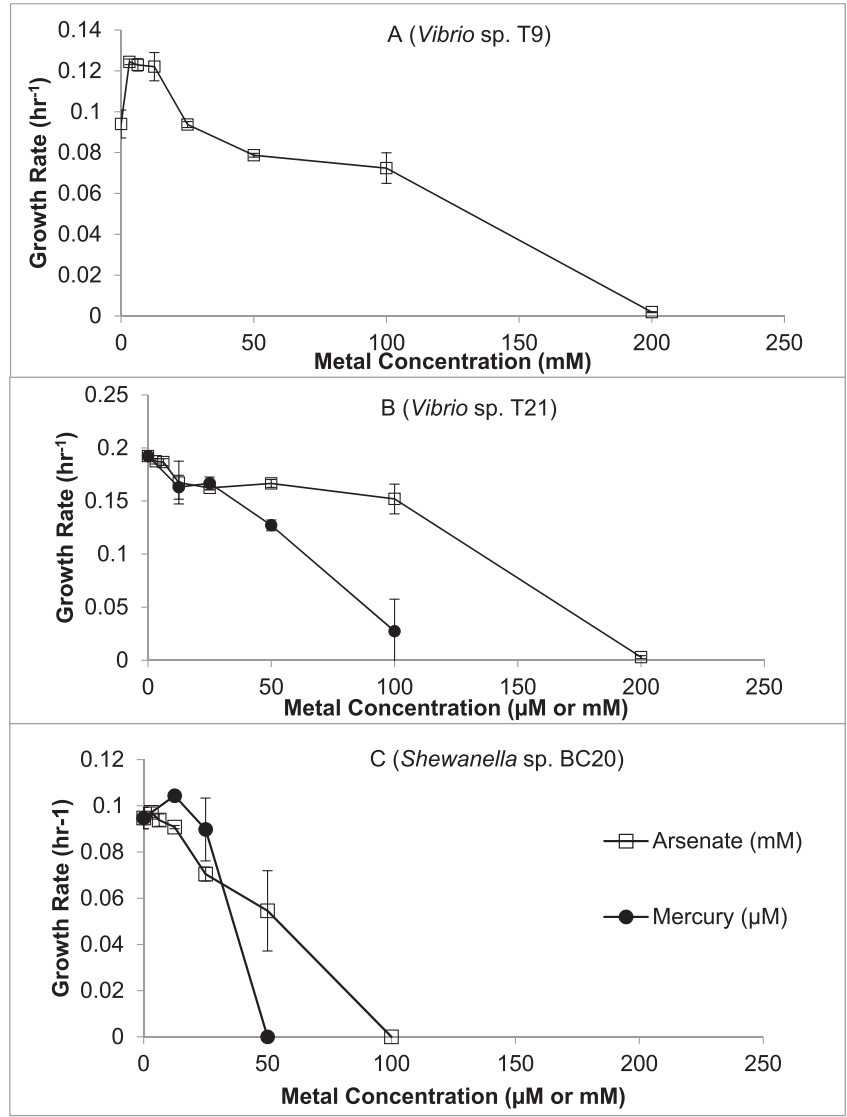

Fig. 2. A-C. Effect of increasing concentrations of arsenate and mercury on growth rates of the three mummichogs bacterial isolates. Each point represents average growth rates of 3 replicates \pm standard deviation. 
genomic island (Fig. 1). Strains Vibrio spp. T9 and T21 both contained class A carbenicillin hydrolyzing $\beta$-lactamases (CARB). The amino acid $\%$ identity of the two CARB genes was $88.3 \%$, indicating they are closely related to each other but not identical (Table 3). Shewanella sp. BC20 harbored a class C $\beta$-lactamase as well as an extended spectrum $\beta$ lactamase (ESBL), bla $a_{\mathrm{OXA}-48}$. The two Vibrio spp. harbored tetracycline (tet34 and tet35) and chloramphenicol resistance genes yet were susceptible to those drugs (Tables 2,3). Vibrio spp. T9 and T21 harbored $q n r S$, which confers resistance to quinolones (Table 3). The Vibrio spp. were phenotypically sensitive to nalidixic acid and most of the fluoroquinolones tested, however Vibrio sp. T21 was intermediately resistant to ofloxacin (Table 2, S1). Further, the genomes harbored many efflux pump gene homologs from various families including ABC, MATE, MFS, RND, and in the Vibrio spp., SMR (Tables S5, S6, S7). The type and abundance found in each were comparable to reference strains (Fig. S2). Notably, Shewanella sp. BC20 contained 13 operons for RND efflux pumps, Vibrio sp. T9 contained 12, and Vibrio sp. T21 contained 13.

\subsection{Metal resistance profiles}

Compared to other metal resistance studies in Vibrio, Vibrio spp. T9 and T21 were resistant to cadmium ( $5 \mathrm{mM}$ ) (data not shown) (He et al., 2016) and arsenate (100 mM) (Liao et al., 2011). Vibrio sp. T21 was also resistant to mercury ( $50 \mu \mathrm{M})$ (Fig. 2A-B) (He et al., 2016). Shewanella sp. BC20 was able to grow with $50 \mathrm{mM}$ arsenate and $25 \mu \mathrm{M}$ mercury (Fig. 2C). All three strains were sensitive to the tested concentrations of arsenite and nickel.

\subsection{Metal resistance genes}

The genomes of the three strains contained operons for arsenate resistance and metabolism (i.e., arsenite oxidation/arsenate reduction) (Table S8, S9). They also contained genes for various P-type ATPases (Table S10). Vibrio spp. T9 and T21 each contained two $\mathrm{P}_{1 \mathrm{~B}-1}$-ATPases and one $\mathrm{P}_{1 \mathrm{~B}-2}$-ATPase. Shewanella sp. $\mathrm{BC} 20$ contained two $\mathrm{P}_{1 \mathrm{~B}-1^{-}}$ ATPases. Not including efflux pump genes, in total, Shewanella sp. BC20 contained 148 homologs for genes involved in metal resistance, while Vibrio sp. T9 had 149, and Vibrio sp. T21 had 154 (Tables S11, S12, S13). The most abundant metal resistance genes among all three genomes were gene homologs for zinc, iron, copper, and nickel resistance.

\subsection{Genomic islands and the mobilome}

We searched for genomic islands in the strains, and more specifically, the carriage of ARGs and metal resistance genes on such islands as possible evidence for co-resistance. The genome of Shewanella sp. BC20 contained 16 genomic islands with one metal resistance gene (Table S14). Vibrio spp. T9 and T21 contained 29 and 23 genomic islands, respectively (Table S15, S16). Vibrio sp. T9's genome had one $10 \mathrm{~kb}$ genomic island that harbored genes encoding for a chloramphenicol acetyltransferase, a class C $\beta$-lactamase, and an MFS transporter (Fig. 1), all genes involved in drug resistance. Vibrio sp. T21's genome contained two genomic islands of interest: a large element $(\sim 25 \mathrm{~kb})$ containing an MFS transporter gene, multidrug ABC transporter gene, and genes involved in horizontal gene transfer (IS3 family transposase) and a smaller genomic island $(\sim 5 \mathrm{~kb})$, which contained a heavy metal translocating P-type ATPase (Fig. 1). Some of the metal resistance genes were located on genomic islands in the Vibrio spp. genomes: three in Vibrio sp. T9 and four in Vibrio sp. T21 (Tables S11, S12). All other ARGs and metal resistance genes are located elsewhere in their respective genomes with no proximity to other ARGs or to genes suggestive of horizontal transfer. We were unable to identify any genes of interest in proximity to phage genes.

\section{Discussion}

The aim of our study was to examine the genetic underpinning of co-selection in multi-drug and metal resistant bacteria isolated from the intestinal microbial community of the mummichog, a common coastal fish. The genome sequences revealed carriage of efflux pump gene homologs, metal resistance genes, and ARGs, including genes of public health concern. Overall, our results indicate that antibiotic and metal resistance are mediated by a variety of factors including chromosomally-encoded resistance genes and potentially efflux pumps. Our results show horizontally-acquired ARGs and metal resistance genes, which highlights the potential for horizontal acquisition of ARGs. Phenotypically, strains were resistant to various classes of antibiotics (primarily different types of $\beta$-lactams) as well as to metals.

The ease by which gene sequences are now obtained by metagenomic approaches has recently led to studies on the abundance and distribution of ARGs in environmental samples (e.g. (Marti et al., 2014; Guo et al., 2017)). While these studies have been useful in assessing hot spots where MDR is likely (e.g., (Berendonk et al., 2015)) they cannot identify the organisms and the mechanisms of gene transfer that partake in ARG transfer from environmental strains to clinical microbes (Perry et al., 2013). Additionally, even though metatranscriptome surveys may inform on the expression of ARGs in the environment (e.g., (Versluis et al., 2015)) how this expression is related to mobilome activities and microbial metabolism cannot be deciphered from such studies. As this information is crucial for the understanding of the ecological framework that underpins the spread of ARGs, metagenomic approaches must be complemented by pure culture studies that shed light on resistant taxa, their ARGs, and potential to mobilize these genes to clinical isolates.

Because MDR among Gram-negative bacteria is of public health concern (Hawkey, 2015), we chose to study three Gram-negative bacteria that represent dominant taxa, Vibrio spp. and Shewanella spp., in our collection (Lloyd et al., 2016) as well as in the mummichog gut microbiome (Givens et al., 2015). Our approach compared genotype (i.e., gene presence) with phenotype to gain an understanding of the carriage, expression, and location of antibiotic and metal resistance genes within the genomes.

Shewanella sp. BC20, isolated from a heavy-metal contaminated estuary, showed resistance to carbapenems, cephalosporins, and penicillins; three classes of drugs to which Shewanella are commonly susceptible (Janda, 2014). The strain showed an elevated resistance profile compared to the 28 out of the 33 environmental Shewanella isolates tested by Tacao et al. (Tacao et al., 2018), with resistance to 9 of the antibiotics reported. Further, the Shewanella sp. BC20 genome harbors a class D $\beta$-lactamase, $b l a_{\text {OXA-48, }}$, with the same upstream and downstream genetic context that others have reported (Tacao et al., 2018). Numerous reports suggest the occurrence of $b l a_{\mathrm{OXA}-48}$ in environmental Shewanella spp. (Poirel et al., 2003) and its horizontal mobility and expression in human pathogens (Almuzara et al., 2017). One of the other isolates studied, Vibrio sp. T21, was intermediately resistant to ofloxacin (Table 2), a fluoroquinolone antibiotic. Resistance to ofloxacin has been attributed to a mutation in the gyrB gene (Singh et al., 2015) and possession of quinolone resistance genes has been described among fish-associated Aeromonas spp. (Chenia, 2016). Quinolones are synthetic antibiotics commonly recommended and used in treatment of Vibrionosis, including $V$. parahaemolyticus infections (Wong et al., 2015).

We identified members of all four Ambler classes of $\beta$-lactamases. Notably, all three strains harbored class B metallo- $\beta$-lactamases (MBLs), which confer resistance to almost all classes of $\beta$-lactam antibiotics. The so-called "New Delhi MBL", is considered a threat to global public health as it is easily mobilizable and has been found in many countries world-wide (Rasheed et al., 2013). Studies have reported on previously unknown MBLs in soil microbiota, which present a clinical threat if acquired by pathogenic bacteria (Gudeta et al., 2016). Thus, the 
occurrence of this gene among environmental organisms may contribute to community-acquired colonization as well as infections (Potron et al., 2011), and suggests the mummichog gut as a reservoir of clinically relevant antibiotic resistant organisms and their associated resistance genes. In order to understand this connection, we looked at the genetic linkage between metal and antibiotic resistance in the genomes. We expected evidence for co-selection suggesting horizontal gene transfer and selection due to heavy metal stress. This expectation was based on: 1) metal resistance genes are often found on mobile genetic elements (McIntosh et al., 2008), 2) the association of metal and antibiotic resistance genes on conjugative plasmids is well-documented (Clowes, 1972), and 3) the fish gut with its abundant nutrients and stable temperature is conducive to microbial growth and gene transfer (Sorensen et al., 2005).

Indeed, we identified two cases where ARGs and metal resistance genes were located on separate genomic islands, clusters of genes of probable horizontal origin (Bertelli et al., 2017). Vibrio sp. T9 contained a $10.8 \mathrm{~kb}$ genomic island with both a class $C$-lactamase and a chloramphenicol acetyltransferase gene homolog (Fig. 1A) and Vibrio sp. T21 had a $\mathrm{P}_{1 \mathrm{~B}-1}$-ATPase, possibly specifying cadmium resistance, on a $5 \mathrm{~kb}$ genomic island (Fig. 1B). This suggests possible past acquisition of these genes. These putative genomic islands do not carry mobilome gene homologs (those involved in conjugation, phage, or transposition). Moreover, we were unable to identify other cases where genes of interest were proximally located to mobilome genes. The one large $(\sim 120 \mathrm{~kb})$ plasmid in Vibrio sp. T21, contained no mobilome, antibiotic, or metal resistance genes. This plasmid did not have any gene homologs indicating potential for conjugation, indicating the plasmid may not be transferrable.

Genome sequences suggest that cross-resistance (efflux pumps) may contribute to co-selection. Each genome harbored many efflux pump gene homologs (66 in Shewanella sp. BC20, 128 in Vibrio sp. T9 and 117 in Vibrio sp. T21 (Tables S5, S6, S7). RND efflux pumps have been implicated in Gram-negative MDR, and both the Shewanella sp. BC20 and Vibrio sp. T21 contained an elevated number of RND-family efflux pump operons compared to previous reports (Lloyd et al., in preparation). This result is consistent with a recent report on the dominance of efflux pump-based cross-resistance in the whole genome sequence of an environmental Pseudomonas strain from a metal-contaminated estuary (Teixeira et al., 2016) and the increased extrusion of antibiotics via RND efflux pumps in marine biofilms exposed to heavy metals (Flach et al., 2017). These results highlight the need to examine cross-resistance as well as co-regulation as mechanisms of co-selection, ideas currently under investigation in our lab. The environmental selection of resistant strains may be the strongest driver of co-selection as was suggested by Forsberg et al., (2014) who assert that microbial community composition rather than horizontal gene transfer is the primary determinant of ARGs in soil.

One advantage of examining co-selection in three individual genomes over community analyses or PCR amplification assays is that it provides direct evidence for co-selection in individual organisms ( $\mathrm{Pal}$ et al., 2017). We tested resistance of three strains to several different antibiotics using two standard methods; the genome sequences of these strains informed us on the presence and/or absence of corresponding resistance genes (Tables 2, S1). All three strains were resistant to ceftazidime using the MIC method, but sensitive in the disk method. Inconsistencies between results obtained with different types of antimicrobial testing methods were previously reported (Lehtopolku et al., 2011). There were several cases where the strains harbored resistance genes but were scored as sensitive to the drug (i.e., tet genes in Vibrio spp.) (Table 3). There were other cases where the strains did not harbor known resistance genes, but were scored as intermediately resistant to the drug (i.e., aminoglycosides in Vibrio spp.). Thus, if a study scores only gene presence, it may either over- or under-estimate the MDR phenotype of a strain. This conclusion is in agreement with recent recommendations for essential verifications if whole genome sequences of pathogens are to serve in resistance profiling in the clinical lab (Lo et al., 2018).

All three strains contained an arsenal of putative metal resistance genes (Tables S11, S12, S13). Notably, the genomes contain homologs to genes known to specify resistance to arsenate, cadmium, and mercury. All three genomes contained arsenate detoxification genes, ars $C$, arsR, ACR3, and arsenate respiration genes (Tables S8, S9). P-type ATPases encoding for the efflux of mono- $\left(\mathrm{P}_{1 \mathrm{~B}-1}\right.$-ATPases $)$ and di-valent ( $\mathrm{P}_{1 \mathrm{~B}-2}$-ATPases) cations (Smith et al., 2014) were identified among all three genomes. Vibrio spp. T9 and T21 contained $\mathrm{P}_{1 \mathrm{~B}-1}$-ATPases (2 copies) and $\mathrm{P}_{1 \mathrm{~B}-2}$-ATPase (1), while Shewanella sp. BC20 contained only $\mathrm{P}_{1 \mathrm{~B}-1}$-ATPases (2) (Table S10) possibly explaining why the Vibrio spp. were resistant to cadmium, while Shewanella sp. BC20 was sensitive. Interestingly, in Vibrio sp. T21, one of the $\mathrm{P}_{1 \mathrm{~B}-1}$-ATPases was located on a predicted genomic island (Fig. 1B).

\section{Conclusions}

In summary, the co-occurrence of multiple antibiotic and metal resistances in three coastal bacterial isolates adds to numerous reports (e.g., (Pal et al., 2017; Henriques et al., 2016)). Coastal marine environments are zones where high microbial productivity, anthropogenic contaminants, and high human population density may converge to create a hot spot for the selection of ARGs and their subsequent inheritance among bacteria.

Our results have implications in both the environment and clinic. Some of the resistance gene homologs identified here were previously shown to occur in human pathogens. Our results provide information on the antibiotic and metal resistome of three strains isolated from the mummichog intestinal microbial community, a potential reservoir of ARGs, and opportunistic human pathogens including Vibrio parahaemolyticus and Shewanella spp. Our findings contribute to the understanding of the mechanisms underlying co-selection in the environment and can also be used to assess the threat of potential emerging zoonotic infections, as well as predict the composition of the resistant community in the environment.

\section{Acknowledgements}

This project was supported with funding from the New Jersey Water Resources Research Institute (USGS-G16AP00071(07043)) at Rutgers University. This material is based upon research supported by the Chateaubriand Fellowship of the Office for Science \& Technology of the Embassy of France in the United States. The platform PARMIC (UMR 5557 Ecologie Microbienne) and associated technicians are also acknowledged for providing equipment, facilities, and valuable advice.

\section{Competing Interests}

The authors have no competing interests to disclose.

\section{Appendix A. Supplementary data}

Supplementary data to this article can be found online at https:// doi.org/10.1016/j.marpolbul.2018.07.051.

\section{References}

Allen, H.K., et al., 2010. Call of the wild: antibiotic resistance genes in natural environments. Nat. Rev. Microbiol. 8, 251-259.

Almuzara, M., et al., 2017. Genetic analysis of a per-2 producing Shewanella spp. strain harboring a variety of mobile genetic elements and antibiotic resistant determinants. J. Glob. Antimicrob. Resist. 11, 81-86.

Bairoch, A., et al., 2007. The universal protein resource (UniProt). Nucleic Acids Res. 35, D193-D197.

Baker-Austin, C., et al., 2006. Co-selection of antibiotic and metal resistance. Trends Microbiol. 14 (4), 176-182.

Bankevich, A., et al., 2012. SPAdes: a new genome assembly algorithm and its 
applications to single-cell sequencing. J. Comput. Biol. 19 (5), 455-477.

Berendonk, T.U., et al., 2015. Tackling antibiotic resistance: the environmental framework. Nat. Rev. Microbiol. 13 (5), 310-317.

Bertelli, C., et al., 2017. IslandViewer 4: expanded prediction of genomic islands for larger-scale datasets. Nucleic Acids Res. 45 (W1), W30-W35.

Bier, N., et al., 2015. Survey on antimicrobial resistance patterns in Vibrio vulnificus and Vibrio cholerae non-O1/non-O139 in Germany reveals carbapenemase-producing Vibrio cholerae in coastal waters. Front. Microbiol. 6 (1179), 1-11.

Blanco, P., et al., 2016. Bacterial multidrug efflux pumps: much more than antibiotic resistance determinants. Microorganisms 4 (1), 1-19.

Bush, K., et al., 2010. Updated functional classification of $\beta$-lactamases. Antimicrob. Agents Chemother. 54 (3), 969-976.

Chenia, H.Y., 2016. Prevalence and characterization of plasmid-mediated quinolone resistance genes in Aeromonas spp. isolated from South African freshwater fish. Int. J. Food Microbiol. 231, 26-32.

Chiou, J., et al., 2015. CARB-17 family of $\beta$-lactamases mediates intrinsic resistance to penicillins in Vibrio parahaemolyticus. Antimicrob. Agents Chemother. 59 (6), 3593-3595.

Cimmino, T., et al., 2016. Whole genome sequence to decipher the resistome of Shewanella algae, a multidrug-resistant bacterium responsible for pneumonia, Marseille, France. Expert Rev. Anti-Infect. Ther. 14 (2), 269-275.

Clincal Laboratory Standards Institute, 2012. Methods for Dilution Antimicrobial Susceptibility Tests for Bacteria That Grow Aerobically; Approved Standard-Ninth Edition.

Clowes, R.C., 1972. Molecular structure of bacterial plasmids. Bacteriol. Rev. 36 (3), 361-405.

Culliton, T.J., 1998. Population: Distribution, Density and Growth. National Oceanic and Atmospheric Administration, pp. 1-33.

Dang, H., et al., 2009. Molecular characterizations of chloramphenicol- and oxytetracy cline-resistant bacteria and resistance genes in mariculture waters of China. Mar. Pollut. Bull. 58 (7), 987-994.

D'Costa, V.M., et al., 2006. Sampling the antibiotic resistome. Science 311 (5759), 374-377.

Flach, C.-F., et al., 2017. Does antifouling paint select for antibiotic resistance? Sci. Total Environ. 590-591, 461-468.

Forsberg, K.J., et al., 2014. Bacterial phylogeny structures soil resistomes across habitats. Nature 509 (7502), 612-616.

Givens, C.E., et al., 2015. Comparison of the gut microbiomes of 12 bony fish and 3 shark species. Mar. Ecol. Prog. Ser. 518, 209-223.

Gudeta, D.D., et al., 2016. The soil microbiota harbors a diversity of carbapenem-hydrolyzing beta-lactamases of potential clinical relevance. Antimicrob. Agents Chemother. 60 (1), 151-160.

Guo, J., et al., 2017. Metagenomic analysis reveals wastewater treatment plants as hot spots of antibiotic resistance genes and mobile genetic elements. Water Res. 123, 468-478.

Gupta, S.K., et al., 2013. ARG-ANNOT, a new bioinformatic tool to discover antibiotic resistance genes in bacterial genomes. Antimicrob. Agents Chemother. 58 (1), 212-220.

Hasan, N.A., et al., 2015. Deep-sea hydrothermal vent bacteria related to human pathogenic Vibrio species. Proc. Natl. Acad. Sci. U. S. A. 112 (21), E2813-E2819.

Hawkey, P.M., 2015. Multidrug-resistant gram-negative bacteria: a product of globalization. J. Hosp. Infect. 89 (4), 241-247.

He, Y., et al., 2016. Antibiotic and heavy-metal resistance of Vibrio parahaemolyticus isolated from fresh shrimps in Shanghai fish markets, China. Environ. Sci. Pollut. Res. 23 (15), 15033-15040.

Henriques, I., et al., 2016. Co-selection of antibiotic and metal(loid) resistance in gramnegative epiphytic bacteria from contaminated salt marshes. Mar. Pollut. Bull. 109 (1), 427-434.

Hooper, D.C., et al., 2015. Mechanisms of drug resistance: quinolone resistance. Ann. N. Y. Acad. Sci. 1354 (1), 12-31.

Janda, J., 2014. Shewanella: a marine pathogen as an emerging cause of human disease. Clin. Microbiol. Newsl. 36 (4), 25-29.

Kahm, M., et al., 2010. Grofit: fitting biological growth curves with R. J. Stat. Softw. 33 (7), $1-21$.

Kang, C.-H., et al., 2016. Antibiotic and heavy metal resistance in Shewanella putrefaciens strains isolated from shellfishes collected from West Sea, Korea. Mar. Pollut. Bull. 112 (1-2), 111-116.

Kearse, M., et al., 2012. Geneious basic: an integrated and extendable desktop software platform for the organization and analysis of sequence data. Bioinformatics 28 (12), 1647-1649.

Lane, D.J., 1991. 16S/23S rRNA sequencing. In: Nucleic Acids Techniques in Bacterial Systematics, pp. 115-147.

Lehtopolku, M., et al., 2011. Inaccuracy of the disk diffusion method compared with the agar dilution method for susceptibility testing of Campylobacter spp. J. Clin. Microbiol. 50 (1), 52-56.

Liao, V.H.-C., et al., 2011. Arsenite-oxidizing and arsenate-reducing bacteria associated with arsenic-rich groundwater in Taiwan. J. Contam. Hydrol. 1-10.

Lima-Bittencourt, C.I., et al., 2007. Multiple antimicrobial resistance in Enterobacteriaceae isolates from pristine freshwater. Genet. Mol. Res. 6 (3), 510-521.

Lloyd, N.A., et al., 2016. Co-selection of mercury and multiple antibiotic resistances in bacteria exposed to mercury in the Fundulus heteroclitus gut microbiome. Curr Microbiol. 73 (6), 834-842.
Lo, S.W., et al., 2018. Breaking the code of antibiotic resistance. Nat. Rev. Microbiol. 16 (5) (262-262).

Lu, Z., et al., 2015. Fate of sulfonamide resistance genes in estuary environment and effect of anthropogenic activities. Sci. Total Environ. 527-528, 429-438.

Madden, T., 2002. Chapter 16: the BLAST sequence analysis tool. In: The NCBI Handbook. National Center for Biotechnology Information, pp. 1-15.

Marti, E., et al., 2014. The role of aquatic ecosystems as reservoirs of antibiotic resistance. Trends Microbiol. 22 (1), 36-41.

McIntosh, D., et al., 2008. Transferable, multiple antibiotic and mercury resistance in Atlantic Canadian isolates of Aeromonas salmonicida subsp. salmonicida is associated with carriage of an IncA/C plasmid similar to the Salmonella enterica plasmid pSN254. J. Antimicrob. Chemother. 61 (6), 1221-1228.

Nealson, K.H., et al., 1991. Isolation and identification of manganese-reducing bacteria and estimates of microbial Mn(IV)-reducing potential in the Black Sea. Deep-Sea Res. 38, S907-S920.

Nonaka, L., et al., 2002. New Mg2 +-dependent oxytetracycline resistance determinant tet 34 in Vibrio isolates from marine fish intestinal contents. Antimicrob. Agents Chemother. 46 (5), 1550-1552.

Pal, C., et al., 2013. BacMet: antibacterial biocide and metal resistance genes database. Nucleic Acids Res. 42 (D1), D737-D743.

Pal, C., et al., 2015. Co-occurrence of resistance genes to antibiotics, biocides and metals reveals novel insights into their co-selection potential. BMC Genomics 16 (964) $1-14$.

Pal, C., et al., 2016. The structure and diversity of human, animal and environmental resistomes. Microbiome 4 (1), 54.

Pal, C., et al., 2017. Metal resistance and its association with antibiotic resistance. Adv. Microb. Physiol. 70, 261-313.

Palzkill, T., 2013. Metallo-beta-lactamase structure and function. Ann. N. Y. Acad. Sci. 1277, 91-104.

Perry, J.A., et al., 2013. The antibiotic resistance "mobilome": searching for the link between environment and clinic. Front. Microbiol. 138, 1-7.

Poirel, L., et al., 2003. Chromosome-encoded Ambler class D beta-lactamase of Shewanella oneidensis as a progenitor of carbapenem-hydrolyzing oxacillinase. Antimicrob. Agents Chemother. 48 (1), 348-351.

Potron, A., et al., 2011. Occurrence of the carbapenem-hydrolyzing $\beta$-lactamase gene blaOXA-48 in the environment in Morocco. Antimicrob. Agents Chemother. 55 (11) 5413-5414.

Rasheed, J., et al., 2013. New Delhi metallo- $\beta$-lactamase-producing Enterobacteriaceae, United States. Emerg. Infect. Dis. 19 (6), 870-878.

Seiler, C., et al., 2012. Heavy metal driven co-selection of antibiotic resistance in soil and water bodies impacted by agriculture and aquaculture. Front. Microbiol. 3 (399), $1-10$.

Singh, P., et al., 2015. Prevalence of gyrA and B gene mutations in fluoroquinoloneresistant and -sensitive clinical isolates of Mycobacterium tuberculosis and their relationship with MIC of ofloxacin. J. Antibiot. 68 (1), 63-66.

Smith, A.T., et al., 2014. Diversity of the metal-transporting P1B-type ATPases. J. Biol. Inorg. Chem. 19 (6), 947-960.

Sorensen, S., et al., 2005. Studying plasmid horizontal transfer in situ: a critical review. Nat. Rev. Microbiol. 3 (9), 700-710.

Soussy, C.J., et al., 2013. Antibiotic Resistance Committee Recommendations 2013 French Society of Microbiology, pp. 1-62.

Tacao, M., et al., 2018. Shewanella species as the origin of blaOXA-48 genes: insights into gene diversity, associated phenotypes and possible transfer mechanisms. Int. J. Antimicrob. Agents 51 (3), 340-348.

Tatusova, T., et al., 2016. NCBI prokaryotic genome annotation pipeline. Nucleic Acids Res. 44 (14), 6614-6624.

Teixeira, P., et al., 2016. Antibiotic and metal resistance in a ST395 Pseudomonas aeruginosa environmental isolate: a genomics approach. Mar. Pollut. Bull. 110 (1), 75-81.

Teo, J.W., et al., 2002. Genetic determinants of tetracycline resistance in Vibrio harveyi. Antimicrob. Agents Chemother. 46 (4), 1038-1045.

Ventola, C.L., 2015. The antibiotic resistance crisis: part 1: causes and threats. Pharm. Ther. 40 (4), 277-283.

Versluis, D., et al., 2015. Mining microbial metatranscriptomes for expression of antibiotic resistance genes under natural conditions. Sci. Rep. 1-10.

Webber, M.A., et al., 2003. The importance of efflux pumps in bacterial antibiotic resistance. J. Antimicrob. Chemother. 51 (1), 9-11.

Wong, K.C., et al., 2015. Antibiotic use for Vibrio infections: important insights from surveillance data. BMC Infect. Dis. 15 (226), 1-9.

Wright, M.S., et al., 2006. Bacterial tolerances to metals and antibiotics in metal-contaminated and reference streams. FEMS Microbiol. Ecol. 58 (2), 293-302.

Wright, V.A., et al., 2010. Berry's creek: a glance backward and a look forward. Int. J. Soi Sediment Water 3, 1-10.

Yoon, S.-H., et al., 2017. Introducing EzBioCloud: a taxonomically united database of $16 \mathrm{~S}$ rRNA gene sequences and whole-genome assemblies. Int. J. Syst. Evol. Microbiol. 67 (5), 1613-1617.

Yousfi, K., et al., 2017a. Current trends of human infections and antibiotic resistance of the genus Shewanella. Eur. J. Clin. Microbiol. Infect. Dis. 36 (8), 1353-1362.

Yousfi, K., et al., 2017b. A novel plasmid, pSx1, harboring a new Tn 1696 derivative from extensively drug-resistant Shewanella xiamenensis encoding OXA-416. Microb. Drug Resist. 23 (4), 429-436.

Zhu, Y.-G., et al., 2017. Continental-scale pollution of estuaries with antibiotic resistance genes. Nat. Microbiol. 2 (16270), 1-7. 